\title{
Memories of an Autopsy: The Effects of Stress Exposure on Suggestibility for a Stressful Event
}

\author{
Elisa Krackow ${ }^{1}$, Vanessa M. Jacoby ${ }^{1} \&$ Joseph R. Scotti ${ }^{1}$ \\ ${ }^{1}$ West Virginia University, Morgantown, WV, USA \\ Correspondence: Elisa Krackow, Department of Psychology, West Virginia University, Morgantown, WV 26506, \\ USA. Tel: 1-304-293-6686. E-mail: Elisa.Krackow@mail.wvu.edu
}

$\begin{aligned} & \text { Received: November 13, } 2012 \\ & \text { Accepted: December 5, } 2012 \quad \text { Online Published: February 21, } 2013 \\ & \text { doi:10.5539/ijps.v5n1p69 }\end{aligned}$ URL: http://dx.doi.org/10.5539/ijps.v5n1p69

\begin{abstract}
The current study examined the effects of stressful life events on memory for a stressful event. Two groups of college students $(N=61)$ were formed for analysis based on the presence or absence of particular stressful life events. Participants then viewed a graphic video depicting an autopsy, and received a memory interview four days later. Results showed similar group performance on correctly leading questions. However, participants in the Specific Stressor-Exposed group were less suggestible to misleading questions than their Specific Stressor-Absent counterparts. Results are discussed in terms of stress sensitization theory and cognitive processing models.
\end{abstract}

Keywords: memory, suggestibility, stress, posttraumatic stress disorder, anxiety

\section{Introduction}

A significant amount of research has been conducted on memory and suggestibility for stressful events (e.g., Goodman, Bottoms, Swartz-Kenney, \& Rudy, 1991; Peterson \& Parsons, 2005; Peterson, Sales, Rees, \& Fivush, 2007; Schooler \& Eich, 2000). History of life stress may be one individual difference factor that influences suggestibility for a stressful event. However, no research to date has examined the relation between an individual's history of life stress and suggestibility for a stressful event.

A variety of theories are relevant to the relation between life stress and suggestibility for a stressful event. Stress sensitization theory posits that individuals become more sensitive to stress as additional stressors beyond the first major stressor are encountered (Hammen, Henry, \& Daley, 2000). Research findings support this theory in the area of depression; that is, a first episode of depression often follows a major life event, such as loss of a loved one, but subsequent depressive episodes result from milder life stressors (Hammen et al., 2000; Stroud, Davila, Hammen, \& Vrshek-Schallhorn, 2011). This theory may also apply to suggestibility. One possibility is that people who have experienced significant life stress may attend more to stressful events, thereby leading to greater accuracy in memory and therefore less suggestibility. Consistent with this view, Pine et al. (2005) found that children who experienced maltreatment, some of whom had a diagnosis of posttraumatic stress disorder, were more likely than children without maltreatment histories to attend to angry or threatening faces. A second possibility is that people who have experienced significant life stress might be more avoidant of stressful life events, and thus encode less information about a stressful event, which might increase their suggestibility. Avoidance has been characterized as a coping response or style in the face of stress (Bryant \& Harvey, 1995), and people with an avoidant coping style may have weaker memories for stressful events. According to trace strength theory and related findings, higher levels of suggestibility occur when memory strength is weaker (Pezdek \& Roe, 1995). Some researchers have found that greater life stress is associated with poorer working memory capacity because unprocessed stressful events compete for cognitive resources (Klein \& Boals, 2001). Therefore, people with greater life stress might be more suggestible regarding stressful life events.

The current study is the first study that we are aware of to examine the impact of experiencing significant life stressors on suggestibility for a stressful event. However, some related research exists. Three studies found that people who endorsed a greater number of stressful life events were more suggestible in general, but these studies included the Gudjonsson Suggestibility Scale which measures suggestibility regarding a story narrative (Drake, 2010; Drake \& Bull, 2011; Drake, Bull, \& Boon, 2008). It is possible that different findings may emerge if an actual stressful life event were used as the to-be-remembered event. Other research has examined whether 
children with maltreatment histories, specifically physical and sexual abuse, recall an anogenital exam better than children with a history of neglect. Although children with and without histories of maltreatment did not differ in their suggestibility regarding the anogenital exam, children with maltreatment histories of physical and sexual abuse were less suggestible to misleading questions about this event than were children who experienced neglect (Eisen, Goodman, Qin, Davis, \& Crayton, 2007).

In the current study, college students completed an assessment measure of life stress and then viewed a video of a stressful event during which a variety of stress ratings were collected. Four days later, participants completed a memory interview with 10 correctly leading questions and 10 misleading questions to measure memory and suggestibility for the stressful video.

\section{Method}

\subsection{Participants}

Sixty-two undergraduate students ( $79 \%$ female) participated in this study. The data reported here are parts of a larger study on stress experiences. The mean age of participants was 19.9 years (age range 18-28). The sample was $87.1 \%$ Caucasian (with $1.6 \%$ self-described as Hispanic), 9.7\% African-American, and $3.2 \%$ Asian. Participants received extra credit for undergraduate courses for their participation. Visual inspection of the data readily revealed that there were two groups of participants: Participants who reported having experienced at least one of the following stressful life events on the History of Psychosocial Stressors questionnaire (see Measures, below): A natural disaster, a technological disaster (e.g., crumbling of a bridge), being the victim of a crime, or abuse/domestic violence. These participants are referred to as the Specific Stressor-Exposed group $(n=46)$ and participants who reported that they had not experienced any of the previously listed life events referred to as the Specific Stressor-Absent group $(n=15)$. Participants commonly experienced six other categories of stressful life events included on the History of Psychosocial Stressors questionnaire that were not used to distinguish the groups: motor vehicle crashes, severe accidental injury, war/terrorism (e.g., being in a war zone), severe/illness/death of someone close to you, serious personal/medical condition, and emergency response (e.g., being exposed to or serving as part of an emergency response team).

\subsection{Measures}

Death Anxiety Scale (Templer, 1970). The Death Anxiety Scale is a 15 -item true-false measure, scores range from $0-15$ with higher scores indicating higher levels of death anxiety. The Death Anxiety Scale has adequate test-retest reliability (.83) and internal consistency (.76). Templer (1970) reported that the Death Anxiety Scale adequately discriminates between death anxiety and general anxiety and is not an indicator of psychopathology in college students. This measure was included to be certain that possible group differences did not account for the study results.

History of Psychosocial Stressors (Scotti et al., 2000). The History of Psychosocial Stressors is a 10-category questionnaire used to measure history of potentially traumatic experiences (e.g., natural disasters, motor vehicle crashes, abuse/domestic violence). Participants indicated whether or not they have experienced each event and if so, they rated the event as: not at all distressing, a little distressing, moderately distressing, quite a bit distressing, or extremely distressing. Sound psychometric properties have been reported in the form of good construct validity and test-retest reliability, $r=.82$ and Kappas $m=.71, m d n=.78, S D=.27$, across administrations (Ruggerio, Del Ben, Scotti, \& Rabalais, 2003).

Video Response Scales. This questionnaire was designed for this study. Participants are asked to rate their emotional reactions to the video (see Procedure). The questionnaire consisted of a words describing five negative personal reactions, anxiety, disgust, nausea, vulnerable, and desire to look away, which were each rated by participants on a $150-\mathrm{mm}$ line with anchor points of $1=$ not at all and $150=$ extremely.

\subsection{Procedure}

All about to be described procedures were approved by the West Virginia University Institutional Review Board.

Session 1. Following the consent process, participants completed a demographics form, the History of Psychosocial Stressors, and the Death Anxiety Scale. Participants then viewed a graphic 20-minute autopsy video (Kriegsman, Lewis, \& Kriegsman, 1999). The original video was approximately 40 minutes in duration; the authors edited it to 20 minutes to prevent reduction of anxiety via habituation. The Video Response Scales were completed at 5, 10,15, and 20 minutes into the video and prior to the start of the video to obtain a baseline measure of the negative states. The video paused and prompted the participants to complete the scales.

Session 2. Four days later, participants completed a memory interview regarding the video. The memory 
interview consisted of an open-ended recall question about the content of the video as well as a series of 10 correctly leading questions ("yes" is the correct response; e.g., "The medical examiner cut the woman's body from the top of the chest to her lower abdomen, didn't he?"; "Blood and fluids were spooned out of the body cavity, weren't they?") and 10 misleading questions ("no" is the correct response; "When cutting the open skull, the medical examiner nicked the ear, didn't he?"; "There was a mark on the side of the woman's face, wasn't there?)." All questions were presented in a tag format to increase the chances of obtaining suggestibility (Krackow \& Lynn, 2003). After completion of the interview, participants were debriefed.

\section{Results}

Preliminary analyses. Two Pearson's correlations were computed to determine: 1) the strength of the relation between the total number of stressful events endorsed (HPS scores) and the number of correct responses to misleading questions, $r=.016, p=.905$, and 2) between the HPS total scores and the number of correct responses to correctly leading questions, $r=-.068, p=.601$.

Next, analyses were conducted to be certain that participants found the video to be stressful. To determine whether specific negative emotions (i.e., anxiety, disgust and vulnerability) increased as a result of viewing the video, three separate Wilcoxin Sign Tests were conducted using the baseline ratings and ratings taken at the end of the video (20 minute mark). Nonparametric statistics were used instead of parametric statistics due to the large differences in sample size across groups. A significant increase in feelings of vulnerability occurred from baseline to the end of video viewing (20 minute mark) in the Specific Stressor-Exposed group, $Z=-3.9, p=.001$, Mbaseline $=7.6, S D=19.1$ vs. Mvideoviewing $=26.7, S D=43.1$. Identical results were found for the Specific Stressor-Absent group, $\mathrm{Z}=-2.2, \mathrm{p}=.028$, Mbaseline $=5.9, S D=11.09$ vs. Mvideoviewing $=30.2, S D=50.5$. Two separate Wilcoxon Sign Tests showed a significant increase in feelings of disgust from baseline to video viewing in the Specific Stressor-Absent group, $\mathrm{Z}=-2.76, p=.006$, Mbaseline $=6.1, S D=12.8$ to Mvideoviewing $=53.4, S D=57.4$ and the Specific Stressor-Exposed group, $Z=--5.09, p=.001$, Mbaseline $=3.4$, $S D=11.5$ to Mvideoviewing $=42.1, S D=44.2$. Anxiety did not increase significantly from baseline to the end of videoviewing in the Specific Stressor-Exposed or Specific Stressor-Absent groups. In addition, a Mann-Whitney $\mathrm{U}$ test was conducted to determine whether participants in the two stress groups differed at the 20 minute mark of the video in three relevant negative emotion scores: anxiety, vulnerability and disgust. There were no significant group differences in anxiety, Mean rank $=30.83$ Specific Stressor-Exposed vs. 31.53 Specific Stressor-Absent, $Z=-.136, p=.892$; nor vulnerability, Mean rank $=30.59$ Specific Stressor-Exposed vs. 32.27 Specific Stressor-Absent, $Z=-.324, p=.746$, nor disgust, Mean rank $=30.82$ Specific Stressor-Exposed vs. 31.57 Stress- Absent, $Z=-.143, p=.886$. It should be noted that these same between-groups analyses were conducted at baseline and there were no initial significant group differences.

Analysis was conducted to determine whether scores on the Death Anxiety Scale differed significantly between stress groups. This analysis showed higher death anxiety in the Specific Stressor-Exposed Group, according to the Mann-Whitney U results, with Mean rank $=33.90$ vs. $22.10, Z=-2.248, p=.025, M=7.5, S D=3.13$ Specific Stressor-Exposed group vs. $M=5.4, S D=2.99$ Stress- Absent Group. However, the mean death anxiety rating in both groups was characterized as being consistent with mean scores of college students and adults not hospitalized for psychiatric illness (Templer \& Ruff, 1971).

Main analyses. Participants in the Specific Stressor-Exposed group made fewer errors in response to misleading questions (i.e., were less suggestible), than participants in the Specific Stressor-Absent group, Mean rank= 28.43 vs. $38.87, Z=-2.024, p=.043, M$ Specific Stressor-Exposed $=3.15, S D=1.68$ vs. $M$ Specific Stressor-Absent $=4.13, S D=1.59, d=-.59$. There were no between groups differences in the number of errors to correctly leading questions, Mean rank $=31.02$ vs. $30.93, \mathrm{Z}=-.017, p=.986, M$ Specific Stressor-Exposed $=$ $2.54, S D=1.34$ vs. $M$ Specific Stressor-Absent $=2.53, S D=1.24, d=.007$.

\section{Discussion}

The current study examined the relation between life stress and suggestibility for a stressful event. Previous research has examined the impact of life stress on suggestibility for a story narrative (Drake, 2010; Drake \& Bull, 2011; Drake et al., 2008). In those studies, individuals with greater life stress were more suggestible to misleading questions under three within-subjects interviewing conditions: (a) when they were simply asked misleading questions; (b) during an interview segment in which negative feedback was provided to the interviewees about the accuracy of their responses, regardless of the response accuracy; and (c) during an interview segment when the identical questions were repeated. In the current study, there was no feedback given to participants about their performance. Instead, participants in our study simply responded to correctly leading and misleading questions. Under these conditions, there were no significant differences in response to correctly 
leading questions for which "yes" was the correct response. However, if participants reported having experienced one or more of a set of serious life stressors (Specific Stressor-Exposed participants) they were less likely to succumb to misleading suggestive questions posed by the interviewer than were participants who did not report experiencing any of the tested stressors (Specific Stressor-Absent participants).

Because prior research shows that people high in anxiety are less suggestible to misleading information (Ridley \& Clifford, 2004, 2006), one set of analyses focused on whether there were group differences in anxiety-related emotions including anxiety, death anxiety, and vulnerability. Although participants in the Specific Stressor-Exposed group reported higher levels of death anxiety than the Specific Stressor-Absent group, participants in both groups reported similar levels of negative emotions including anxiety during the video. Negative emotions (e.g., vulnerability) increased compared to baseline levels in both the Specific Stressor-Exposed and Specific Stressor-Absent Groups as people watched the autopsy video but anxiety did not increase. Therefore, at least self-reported situational anxiety ratings do not appear to be responsible for the decreased suggestibility. However, the results of the current study are consistent with the literature on anxiety and eyewitness memory which finds anxious participants to incorporate misleading information into memory, but also finds no significant differences in responses to information consistent with the to-be-remembered material (Ridley \& Clifford 2004, 2006). The results of the current study are also consistent with previous literature showing a decrease in suggestibility for maltreated children (Eisen et al., 2007).

Consistent with stress sensitization theory, it may be that individuals with a history of particular psychosocial stressors attended better to the video due to being more sensitive to stressful events. A model posed by Williams and colleagues (Williams, Watts, MacLeod, \& Mathews, 1997) may also be pertinent here. Although the model is specific to anxiety, it may be relevant to life stress. According to Williams et al. (1997), when a stimulus is encountered, its threat value is appraised. If the threat value is appraised as being high, people with anxiety, or in this case a history of life stress, may orient cognitive processing resources toward the threat, whereas nonanxious others naturally orient cognitive processing resources away from the threat.

The findings of the current study represent novel findings in the literature. Therefore, future studies should attempt to replicate and extend these results.

\section{References}

Bryant, R. A., \& Harvey, A. G. (1995). Avoidant coping style and posttraumatic stress following motor vehicle accidents. Behaviour Research and Therapy, 33, 631-635. http://dx.doi.org/10.1016/0005-7967(94)00093-Y

Drake, K. E. (2010). Interrogative suggestibility: Life adversity, neuroticism, and compliance. Personality and Individual Differences, 48, 493-498. http://dx.doi.org/10.1016/j.paid.2009.11.030

Drake, K., \& Bull, R. (2011). Individual differences in interrogative suggestibility: Life adversity and field dependence. Psychology, Crime \& Law, 17, 677-687. http://dx.doi.org/10.1080/10683160903511967

Drake, K. E., Bull, R., \& Boon, J. C. W. (2008). Interrogative suggestibility, self-esteem, and the influence of negative life-events. Legal and Criminological Psychology, 13, 299-307. http://dx.doi.org/10.1348/135532507X209981

Eisen, M. L., Goodman, G. S., Qin, J., Davis, S., \& Crayton, J. (2007). Maltreated children's memory: Accuracy, suggestibility, and psychopathology, Developmental Psychology, 43, 1275-1294. http://dx.doi.org/10.1037/0012-1649.43.6.1275

Goodman, G. S., Bottoms, B. L., Swartz-Kenney, D., \& Rudy, L. (1991). Children's testimony about a stressful event: Improving children's reports. Journal of Narrative \& Life History, 1, 69-99.

Hammen, C., Henry, R., \& Daley, S. E. (2000). Depression and sensitization to stressors among young women as a function of childhood adversity. Journal of Consulting and Clinical Psychology, 68, 782-787. http://dx.doi.org/10.1037/0022-006X.68.5.782

Klein, K., \& Boals, A. (2001). Expressive writing can increase working memory capacity. Journal of Experimental Psychology: General, 130, 520-533. http://dx.doi.org/10.1037/0096-3445.130.3.520

Krackow, E., \& Lynn, S. J. (2003). Is there touch in the game of Twister? The Effects of innocuous touch and suggestive questions on children's eyewitness memory. Law and Human Behavior, 27, 589-604. http://dx.doi.org/10.1023/B:LAHU.0000004888.52210.35

Kriegsman, J., Lewis, A., \& Kriegsman, M. (1999). Autopsy: Through the eyes of death's detectives [Motion Picture]. United States: KHK films. 
Pine, D. S., Mogg, K., Bradley, B. P., Montgomery, L., Monk, C. S., McClure, E., ... Kaufman, J. (2005). Attention bias to threat in maltreated children: Implications for vulnerability to stress-related psychopathology. The American Journal of Psychiatry, 162, 291-296. http://dx.doi.org/10.1176/appi.ajp.162.2.291

Pezdek, K., \& Roe, C. (1995). The effect of memory trace strength on suggestibility. Journal of Experimental Child Psychology, 60, 116-128. http://dx.doi.org/10.1006/jecp.1995.1034

Peterson, C., \& Parsons, B. (2005). Interviewing former 1- and 2-year-olds about medical emergencies five years later. Law and Human Behavior, 29, 743-754. http://dx.doi.org/10.1007/s10979-005-8378-0

Peterson, C., Sales, J. M., Rees, M., \& Fivush, R. (2007). Parent-child talk and children's memory for stressful events. Applied Cognitive Psychology, 21, 1057-1075. http://dx.doi.org/10.1002/acp.1314

Ridley, A., \& Clifford, B. R. (2004). The effects of anxious mood induction on suggestibility to misleading post-event information. Applied Cognitive Psychology, 18, 233-244. http://dx.doi.org/10.1002/acp.963

Ridley, A., \& Clifford, B. (2006). Suggestibility and state anxiety: How the two concepts relate in a source identification paradigm. Memory, 14, 37-45. http://dx.doi.org/10.1080/09658210444000494

Ruggiero, K. J., Del Ben, K., Scottie, J. R., \& Rabalais, A. E. (2003). Psychometric properties of the PTSD checklist-Civilian Version. Journal of Traumatic Stress, 16, 495-502. http://dx.doi.org/10.1023/A:1025714729117

Schooler, J. W., \& Eich, E. (2000). Memory for emotional events. Oxford, England: Oxford University Press.

Scotti, J. R., Ruggiero, K. J., Rabalais, A., Parker, L., Smith, T., \& Del Ben, K. (2000). History of psychosocial stressors: Conceptualization, utilization, validity, and test-retest reliability. Poster presented at the $34^{\text {th }}$ annual convention of the Association for Advancement of Behavior Therapy, New Orleans, LA.

Stroud, C. B., Davilia, J., Hammen, C., \& Vrshek-Schallhorn, S. (2011). Severe and nonsevere events in first onsets versus recurrences of depression: Evidence for stress sensitization. Journal of Abnormal Psychology, 120, 142-154. http://dx.doi.org/10.1037/a0021659

Templer, D. I. (1970). The construction and validation of a death anxiety scale. The Journal of General Psychology, 82, 165-177. http://dx.doi.org/10.1080/00221309.1970.9920634

Templer, D. I., \& Ruff, C. F. (1971). Death anxiety scale means, standard deviations, and embedding. Psychological Reports, 29, 173-174. http://dx.doi.org/10.2466/pr0.1971.29.1.173

Williams, J. M. G., Watts, F. N., MacLeod, C., \& Matthews, A. (1997). Cognitive Psychology and Emotional Disorders (2nd ed.). London, UK: John Wiley \& Sons Ltd.

\section{Note}

Note 1 . All preliminary and main analyses were re-run using their parametric counterparts. All results remained the same except the $p$ value increased to from .043 to .052 for misleading questions. 